\title{
Changes of occlusal plane inclination after orthodontic treatment with four premolars extraction in dento-alveolar bimaxillary protrusion cases
}

\author{
N.R. Yuliawati Zenab, Tono S. Hambali, Jono Salim, Endah Mardiati \\ Department of Orthodontics Faculty of Dentistry Universitas Padjadjaran
}

\section{ABSTRACT}

The purpose of this study was to find out whether there were changes in occlusal plane inclination after fixed orthodontic treatment of bimaxillary protrusion cases where extraction of four first premolars were needed using the standard Edgewise appliances. The sample were fourteen orthodontic patients, aged above sixteen years old, no sexual discrimination, treated with fixed appliances at Orthodontic Specialist Clinic Faculty of Dentistry Universitas Padjadjaran. The method was pre-post design which compared occlusal plane inclination obtained from tracings of lateral cephalograms before and after orthodontic treatment. The results were calculated with the paired t-test analysis. The study revealed that there were no significant changes in occlusal plane inclination after the orthodontic treatment.

Key words: Occlusal plane inclination, premolars extraction, standard Edgewise

\section{INTRODUCTION}

In addition to crowding, starting from mild to severe, skeletal disorder cases such as dentoalveolar bimaxillary protrusion cases are also often found in Indonesia. Dento-alveolar bimaxillary protrusion is a disorder where maxillary and mandible move forward excessively (prognathic) accompanied by all the teeth of both jaws. In addition, according to Soelarko ${ }^{1}$ because canines of the Indonesian people are located in front of the orbital plane and the jaw is more forward compared to Caucasoid race, the Indonesian profile is more convex.

In dento-alveolar bimaxillary malocclusion cases, the four first-premolar extraction is performed and followed by retraction of six maxillary and mandibular anterior teeth. It is preferred that in bimaxillary protrusion case treatment, fixed orthodontic appliance are used..$^{2,3}$ In dento-alveolar bimaxillary protrusion, the most general treatment is premolar extraction, because the position of premolar which is very advantageous, i.e. between anterior and posterior segments. ${ }^{4}$

Occlusal plane inclination changes also can occur due to the mesial molar movement (anchorage loss). Kocadereli ${ }^{5}$ stated that it is necessary to give attention to the posterior anchorage so the position is not changed during anterior retraction in bimaxillary protrusion treatment. In addition, the occlusal plane inclination changes can also be caused by (changes in molar and incisives) extrusion and intrusion. ${ }^{5}$

The occlusal plane inclination change should not happen during the dento-alveolar

Correspondence author: N.R. Yuliawati Zenab, Department of Orthodontics Faculty of Dentistry Universitas Padjadjaran Jl. Sekeloa Selatan No. 1 Bandung, West Java-Indonesia, Tel./Fax: +6222-2504985/2532805 
bimaxillary protrusion treatment by four firstpremolar extraction because it can result in temporomandibular joint disorder (TMJ)..$^{5,7,8}$ The occlusal plane inclination changes can affect dental occlusion. Each occlusal rotation of $1^{\circ}$ can result in $0.5 \mathrm{~mm}$ change of dental occlusion relationship. ${ }^{6}$ In addition, the change also can result in treatment result instability. ${ }^{9}$

The purpose of this study was to obtain occlusal plane inclination change during the treatment of dento alveolar bimaxillary protrusion cases with four first-premolar extraction using Edgewise standard fixed orthodontic appliance at the Orthodontic Specialist Clinic, Faculty of Dentistry, Universitas Padjadjaran.

\section{MATERIALS AND METHODS}

The study was a pre-post design study by comparing lateral cephalogram images before and after treatment. The collected data were analysed using paired t-test analysis. The materials were 28 lateral cephalogram images before and after treatment, which were collected from 14 patients with dento-alveolar bimaxillary protrusion.

The sample criteria included: patient with dento-alveolar bimaxillary protrusion; treated with four first-premolar extraction; both maxilary and mandibular; and treated using fixed orthodontic appliance with Edgewise standard technique; male and female patient above 16 years old, complete and good (before and after treatment) lateral cephalogram images. The criterion for exclusion was unclear lateral cephalogram image sample and patients who did not need four premolars extraction.
The first step was to provide sample code for identification. Tracing was performed by one operator using $4 \mathrm{H}$ pencil. The next step was to determine $\mathrm{S}$ and $\mathrm{N}$ dot, and occlusal plane to analyze cephalogram according to Steiner and followed by making orientation line (SN and occlusal line). Occlusal plane angle was measured using protractor (Ormco) on the SN and occlusal lines meeting point (Steiner) and noted. These steps were performed twice on the same lateral cephalogram image by the same operator with one week interval time to maintain data validity. Occlusal plane angle determination (SN line with occlusal line) was seemed at Figure 1.

\section{RESULTS}

Table 1 shows occlusal plane inclination $\mathrm{BO}$ $\mathrm{SN}$ change of $-0.41^{\circ}\left(\mathrm{SD}=2 \cdot 48^{\circ}\right)$. BO-SN inclination average value results before and after the

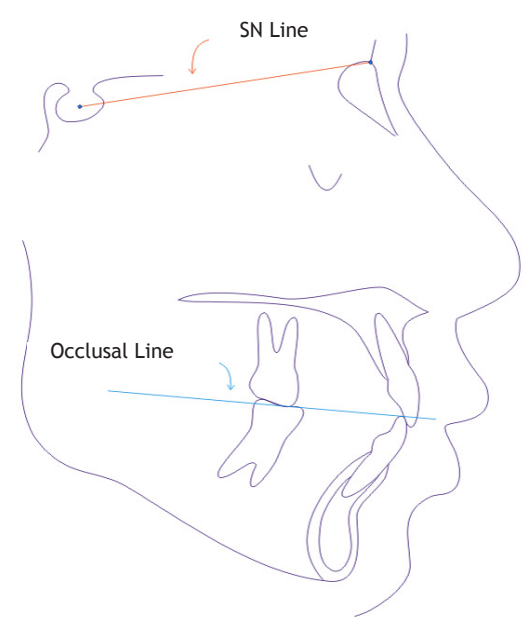

Figure 1. Occlusal plane angle determination (SN line with occlusal line).

Table 1. Occlusal inclination average difference test before and after treatment.

\begin{tabular}{llccl}
\hline BO-SN inclination & & Before & After & Difference \\
\hline Tracing 1 & $\bar{x}(S D)$ & $14.93(4.56)$ & $14.30(3.88)$ & $-0.63(2.87)$ \\
Tracing 2 & $\bar{x}(S D)$ & $14.29(3.88)$ & $14.09(3.52)$ & $-0.20(2.36)$ \\
Tracing 1 and 2 & $\bar{x}(S D)$ & $14.61(4.19)$ & $14.20(3.64)$ & $-0.41(2.48)$ \\
\hline
\end{tabular}

Note: (BO) occlusal plane; (SN) sella-nasion; $(P)$ confidence value ( $p<0.01$ very significant, $p<0.05$ significant, $p>0.05$ not significant); (NS) Not significant ( $p>0.05)$.

Table 2. Occlusal plane inclination change paired data before and after the treatment.

\begin{tabular}{cccccc}
\hline BO-SN inclination & Before $\left.^{\circ}\right)$ & After $\left({ }^{\circ}\right)$ & $\mathrm{t}_{\text {count }}$ & P value & Feature \\
\hline Tracing 1 and 2 & $14.61(4.19)$ & $14.20(3.64)$ & -0.62 & 0.546 & NS \\
\hline
\end{tabular}

Note: $x$ Average; (SD) difference deviation standard. 
treatment between tracing 1 and 2 in the table are recalculated statistically to determine the significance. The results are seen in the following (Tab. 2).

Table 2 shows that BO-SN inclination before and after treatment was $14.61^{\circ}\left(S D=4.19^{\circ}\right)$, while BO-SN inclination after treatment between the two tracings was $14.20^{\circ}\left(S D=3.64^{\circ}\right)$. From paired data $t$-test result, $t_{\text {count }}$ value is 0.62 . The $p$ value gained with a confident level $(\alpha)=95 \%$ was 0.546 . This indicates that $p$ value $>0.05 \quad(p=0.546)$, that means the occlusal plane inclination change was statistically not-significant.

\section{DISCUSSION}

The study was a pre-post design research analysed with paired data t-test from 28 lateral cephalogram of 14 patients with dento-alveolar bimaxillary protrusion with four first-premolar extractions treated using Edgewise standard fixed orthodontic appliance. The occlusal plane angle measurement in this study based on Steiner analysis toward S-N plane (Sella-Nasion Plane), and the average angle is $14.5^{\circ}$. The result shows that even though the obtained occlusal plane inclination change average was $-0.41^{\circ}$, which means that after treatment, occlusal plane inclination becomes smaller compared to before treatment, the occlusal plane inclination change was not statistically significant with $p$ value $>0.05$ $(p=0.546)$.

This statistically insignificant occlusal plane inclination change could be resulted from several possibilities, i.e. maximal anchorage use during fixed orthodontic treatment. On the other hand, in the samples taken there maybe no posterior and anterior intrusion and extrusion, and this study only uses small sample (14 samples).

Maximum anchorage that was usually used in Orthodontic Specialist Clinic, Faculty of Dentistry, Universitas Padjadjaran was performed using palatal bar, head gear, and engaging second molar as reinforced anchorage to prevent anchorage loss. According to Proffit ${ }^{10}$, anchorage is resistance against undesirable dental movement. If anterior teeth were going to be retracted to prevent posterior teeth moving forward, the posterior anchorage can be added by engaging the second molar. According to Kocadereli ${ }^{5}$, to prevent anchorage loss of posterior teeth during anterior retraction in dento-alveolar bimaxillary protrusion with four first-premolar extraction, it necessary to watch the anchorage. In addition, changes of position of posterior teeth can alter vertical dimension, resulting in increase of occlusal plane inclination. So, it can be concluded that maximum anchorage can prevent posterior dental changes in class I dento-skeletal dento-alveolar bimaxillary protrusion treatment and eventually prevent the occlusal plane changes.

The second possibility that cause insignificant change in the study because there was no posterior and anterior intrusion and extrusion movement in the sample. This correspondent with Rotberg ${ }^{11}$ statement, occlusal plane inclination changes was resulted from posterior or anterior intrusion and extrusion as a consequence of the treatment process. In addition, according to Miyazaki et al. ${ }^{12}$ in adults who received treatment using Edgewise standard fixed orthodontic appliance with four first-premolar extraction in protrusion or crowding cases after the treatment shows additional overjet and overbite. These overjet and overbite changes can be caused by posterior and anterior intrusion and extrusion that eventually results in occlusal plane change.

According to the writer, there are two possibilities that cause occlusal plane inclination change, i.e. the occlusal plane angle becomes smaller by mandible incision extrusion which results in anti clock-wise rotation extrusion of molars or intrusion of mandibular incisors can also cause alteration of occlusion plane. These molar and incisive changes will cause occlusal plane clockwise rotation. This statement also supports Ahn et al. ${ }^{13}$ who stated that vertical dimension increase often causes clockwise mandible rotation. While Braun et al. ${ }^{6}$ stated that each one degree rotation of occlusal plane will result in a half millimetre change in dental occlusal relation. At the other hand, Burstone et al. ${ }^{9}$ stated that in patient with too large vertical dimension, it is considered to perform surgery.

The results supports Kim et al. ${ }^{7}$, Kocadereli ${ }^{5}$, and Staggers ${ }^{9}$ who stated that the occlusal plane should not be changed in the treatment with four first molar extraction of dento-alveolar bimaxillary protrusion case because it will result in vertical dimension change. 
This study showed that there was no occlusal plane inclination change. The result corresponds with Graber et al. ${ }^{14}$ statement that occlusal plane angle should be maintained. Occlusal plane increase will affect masticatory muscle balance. According to Burstone et al. ${ }^{9}$ occlusal plane in patients with fine posterior occlusion should be maintained during orthodontic treatment. The occlusal plane change in the posterior that causes posterior axial inclination will change and lead to treatment result instability.

The result was different with the Braun et al. ${ }^{7}$ result. In his study, there was occlusal plane inclination change using class II and class III elastics, because of the posterior dental extrusion. The differences were on the selection and sample size, treatment technique and cases used in the study and different race of the sample.

\section{CONCLUSION}

Occlusal plane inclination changes after treatment in dento-alveolar bimaxillary protrusion cases with four first-premolar extraction using Edgewise fixed orthodontic appliance treatment was $-0.41^{\circ}$, it meant that the occlusal plane inclination become smaller compared before treatment. But statistically, the paired data t-test obtains a $p$ value of $>0.05(p=0.546)$ showing that the occlusal plane inclination change after the treatment is statistically insignificant.

\section{REFERENCES}

1. Soelarko. Beberapa pengukuran chepalometrik pada tengkorak-tengkorak Indonesia sebagai dasar bagi norma-norma prothetik Bangsa Indonesia. Bandung: Angkasa; 1979. p. 205.

2. Farrow $\mathrm{AL}$, Zarrinnia $\mathrm{K}$, Azizi $\mathrm{K}$. Bimaxillary protrusion in Black Americans - An esthetic evaluation and the treatment considerations. Am J Orthod Dentofac Orthop 1993;104(3):240-50.
3. Hagler BL, Lupini J, Johnston LE. Long-term comparison of extraction and nonextraction alternatives in matched samples of African American patients. Am J Orthod Dentofac Orthop 1998;114(4):393-403.

4. Shearn BN, Woods MG. An occlusal and cephalometric analysis of lower first and second premolar extraction effects. Am J Orthod Dentofac Orthop 2000;117(3):351-61.

5. Kocadereli I. The effect of first premolar extraction on vertical dimension. Am J Orthod Dentofac Orthop 1999;116(1):41-5.

6. Braun S, Legan HL. Changes in occlusion related to the cant of the occlusal plane. Am J Orthod Dentofac Orthop 1997;111(2):184-8.

7. Kim TK, Kim JT, Mah J, Yang WS, Baek SH. First or second premolar extraction effects on facial vertical dimension. Angle Orthodontist 2005;75(2):173-8.

8. Staggers JA. Vertical changes following first premolar extractions. Am J Orthod Dentofac Orthop 1994;105(1):19-24.

9. Busstone CJ, Marcotte MR. Problem solving in orthodontics. Chicago: Quintessence Publishing Co., Inc.; 2001. p. 31-50.

10. Proffit WR, Fields HW. Contemporary orthodontics. $3^{\text {rd }}$ ed. St. Louis: Mosby Inc.; 2000. p. 161-2,251-6,304,309-10.

11. Rotberg $S$, Fried N, Kane J, Shapiro E. Predicting the "wits" appraisal from the ANB Angle. Am J Orthod Dentofac Orthop 1980;77(6):636-42.

12. Miyazaki H, Motegi E, Yatabe K, Isshiki Y. Occlusal stability after extraction orthodontic therapy in adult and adolescent patients. Am J Orthod Dentofac Orthop 1998;114(5):530-7.

13. Ahn JG, Schneider BJ. Cephalometric appraisal of posttreatment vertical changes in adult orthodontic patients. Am J Orthod Dentofac Orthop 2000;118(4):378-84.

14. Graber TM, Vanarsdall RL. Orthodontics: current principles and techniques. $2^{\text {nd }}$ ed. St. Louis: Mosby Year Book Inc.; 1994. p. 62-3,305-7,641. 